\title{
The Role of Gender in
}

\section{Descriptive Representation}

\author{
CINDY SIMON ROSENTHAL, UNIVERSITY OF OKLAHOMA
}

\begin{abstract}
This article broadens consideration of the gender gap from voting differences to the larger question of affective preferences for descriptive representation (Pitkin 1967). The results, based on a 1993 survey of 416 individuals, suggest that women are far more likely than men to be "gender conscious" in their evaluation of a candidate or a preferred representative. Differences among the 224 women in the sample can be traced to at least four sources. Group interests and feminist attitudes are positive sources of women's preferences for descriptive representation. Conversely, conservative political views deter some women from supporting women in politics. The results also provide partial support for Carroll's (1987) psychological and economic autonomy thesis. Finally, the results suggest that in part the "gender gap" may be a generational gap most prevalent among "baby boomers."
\end{abstract}

The 1992 election demonstrated that gender matters. Cook, Thomas, and Wilcox (1994) provide ample evidence from the campaign trails that candidates tailored their appeals and voters and activists responded on the basis of gender. In turnout, partisanship and presidential vote choice, a "gender gap" between women and men continued to be evident (Frankovic 1982; Mueller 1987; Bendyna and Lake 1994). Gender differences, though modest and operating at the margins in some races, affected the fates of candidates in various races.

What is not clear from analyses of the gender gap is whether something other than group interests, party, or ideology forms a basis for voters' calculus. For example, in Cook's (1994) analysis of 1992 U.S. Senate races involving match-ups between a male and a female candidate, women were more likely to vote for the female candidate and to respond in exit polls that it was very

NOTE: I would like to thank Walter Stone, editor, and the reviewers of the Political Research Quarterly for their insightful and constructive critique of this manuscript. In addition, I appreciate the support and assistance of Robert Bursik and Harold Grasmick, co-directors of the Oklahoma City Survey. My research was completed while serving as a Carl Albert Congressional Fellow at the Carl Albert Congressional Research and Studies Center, University of Oklahoma. 
important to elect more women to the U.S. Senate. Women also voted in greater numbers for an antifeminist Republican Charlene Haar in South Dakota's U.S. Senate contest. Is the South Dakota race an anomaly or does it point to the possibility that some women prefer descriptive representation?

This study analyzes affective attachments to descriptive or "standing for" representation (Pitkin 1967). Do men and women differ in their preferences for same-gender representation? If so, then what factors seem to explain this "gender gap"? Finally, why do some women express a stronger preference for same-gender representation than other women? For its theoretical framework, the paper borrows both from analyses of the gender gap and research on gender consciousness.

\section{Gender and the Problem of Representation}

Some scholars have argued that gender consciousness explains the subtle nuances that distinguish how men and women engage and participate in the political world. Tolleson Rinehart (1992: 32) defines gender consciousness as the "recognition that one's relationship to the political world is at least partly but nonetheless particularly shaped by being female or male." Gender consciousness arguably precedes "actions in and on one's behalf" and is the "unobserved" connection between attitude and behavior (Tolleson Rinehart 1992: 166). Research by Huddy and Terkildsen (1993a and 1993b) provides evidence that such a connection exists in stereotypes that condition voters' responses to female and male candidates.

A preference for same-gender descriptive representation gets to the heart of whether gender consciousness undergirds political behavior. For women, support for a female candidate may reflect a desire for representation as "standing for" or as "acting for" or both. Since not all women share the same policy concerns, descriptive and substantive representation may sometimes be at odds. Tolleson Rinehart (1994: 68-70) suggests that women who embrace more traditional gender roles share some gender consciousness with feminists even when their stated interests seem to be in conflict.

Given that structural barriers limit the number of women candidates on the ballot (Darcy et al. 1987), evidence of the "gender gap" in voting behavior arguably reflects only the behavior of the most gender conscious women. Without more female candidates, women cannot demonstrate a preference for descriptive representation. Moreover, a vote choice framed by the crosspressures of ideology, partisanship, race, and group interests may mask the extent of or mitigate the effects of gender consciousness.

Such limitations argue for an attempt to probe voters' representational attachments, even if such preferences must be posed in hypothetical terms. As Eulau and Karps (1977: 236) note, elections and voting constitute "only one 
of the links between representative and represented" and not even the most critical one. Therefore, this research uses a specially constructed scale of representation preferences to test whether some level of gender consciousness shapes how men and women evaluate candidates. This study also provides an opportunity to explore Carroll's (1987) economic and psychological autonomy thesis as a source of differences among women.

Carroll argues that women who are economically and psychologically independent from men are the most likely to express political unity with other women. Other studies also have linked economic status, particularly housewives and working women, with differences in the political behavior of women (eg., Deitch 1987; Poole and Ziegler 1985; Gurin 1986). Carroll (1987: 250) defines economic autonomy by occupation, marital status, and education, and measures psychological independence by support for the statement that "women should have an equal role with men in running business, industry and government." Using the 1980 and 1982 National Election Studies, she finds that women who are both economically and psychologically independent were least likely to vote for and approve of President Reagan, more than 20 percentage points less than the least autonomous women and men who shared similar demographic characteristics (Carroll 1987: 253).

This study develops Carroll's thesis beyond the single indicator of psychological autonomy. At the same time, three competing explanations are considered: (1) the role of political ideology as indicated by feminist attitudes and liberal-conservative views; (2) the degree of group consciousness; and (3) the possibility that women who are more supportive of female candidates may be part of a specific age cohort.

Ideology generally has little impact on voters in the United States (Campbell et al. 1960; Converse 1964; Niemi and Weisberg 1984; Neuman 1986), and feminism has failed to mobilize women into a self-conscious, unified political movement (Sears and Huddy 1990). Nonetheless, Sapiro (1991: 12) notes that feminist values of gender equality and fair treatment have gained widespread acceptance. Feminist attitudes and liberal political views are expected to have a positive association with preference for descriptive representation for some women.

Substantive representation presumes that women public officials will "act for" and pursue the interests of women as a group, and there is considerable evidence to support that presumption (see for example Mandel and Dodson 1992; Thomas 1994). Identification with women's group interests is expected to show a positive association with women's support for same-gender representation.

Finally, the effects of age on descriptive representation preferences are considered. The combination of life experiences and childhood socialization 
arguably make "baby boom" women most likely to show strong preferences for descriptive representation. Not only did the "baby boom" generation come of age during the blossoming of feminism; women in their forties may also be distinguished by their cumulative life experiences (i.e., gender discrimination in the workplace, divorce, and struggles as single parents). It is hypothesized that these women will have some of the strongest preferences for female representation.

\section{Research Design}

Data were gathered as part of the 1993 Oklahoma City survey. ${ }^{1}$ The sample consists of 416 adults (18 and older) drawn at random using the R. L. Polk Directory and contacted for personal interviews. Questionnaires were administered by paid, trained interviewers in the respondents' homes; refusals and those who were unavailable for interviews were replaced by random substitution in the same neighborhood. Approximately 40 percent of the final sample were not in the original sampling frame but rather were substitutes selected randomly according to the prescribed protocol.

The sampling procedure generated a sample which compares favorably to the population of the community in selected demographic characteristics (U.S. Bureau of the Census 1990). The sample also compares favorably with the U.S. population. The sample is 46 percent male (192), 54 percent female (224). Racial composition of the sample consists of 333 whites ( 79.5 percent), 66 blacks ( 15.8 percent), and 20 other nonwhites ( 4.5 percent). Mean age for the sample is 45.5 years.

\section{Variables}

The dependent variable comprises four items which asked respondents to indicate a preference between a male or a female candidate or officeholder. The questions follow a Likert-scale format and provide five response categories ranging from "a woman much more than a man" to "a man much more than a woman" with a middle category of "a man and a woman about equally." For example, respondents were asked: "If you had a problem requiring a government solution, would you be more comfortable dealing with a man or a woman in public office?" The other three questions asked whether a man or a woman would be more trusted by the respondent, be more likely to share the same concerns about the country, and be most likely to win the respondent's vote. The items were developed specifically for this survey and were found to be

${ }^{1}$ Data from the Oklahoma City Survey are not generally available, however researchers interested in gaining access to the particular questions and responses utilized in this article can contact the author for assistance. 
reliable in pre-tests. Scores were recoded, standardized and summed for a scale score. A high score indicates stronger preference for female representation. The four-item scale produced a single factor solution (Eigenvalue = 2.305) and an Alpha reliability of .753 (for men only, Eigenvalue 2.289, Alpha $=.750)$.

The principal independent variables include two scales (measuring feminist attitudes and psychological autonomy), a measure of identification with women as a political group, conservative-liberal political orientation, and demographic variables of education, age, marital status, and income. Respondents were asked to describe their political attitudes, choosing from seven options (e.g., extremely liberal, liberal, slightly liberal, moderate, slightly conservative and so on). A high score on the measure indicates a more conservative orientation. In multiple regression analysis of the full sample, gender is used as a dummy variable coded " 1 " for male and " 0 " for female. In order to test for women's economic autonomy, analyses using women only employ an economic status variable which is the sum of each respondent's z-score on the variables of education and the woman's own income. Four categories of marital status are used: never married, married, separated or divorced, and widowed. Political party was also analyzed but failed to demonstrate any significant association in either the categorical or multivariate analysis.

Three items dealing with attitudes about women's roles in government and politics were asked of respondents. These questions are based on previous research (Klein 1984). Specifically, selecting from four agree/disagree response categories, survey participants were asked (1) if government would be better off with more women in it; (2) whether women are as qualified as men for business, industry, and government; and (3) whether women as a group have enough political influence. The first two items produced a feminist attitude scale with a single factor solution (Eigenvalue $=1.562$ ) and an Alpha reliability of .717 for the full sample (for men only Eigenvalue $=1.475$, Alpha $=.644$ ). As anticipated, factor analysis of all three items showed the third item to tap a separate construct, and thus the item was used as an independent measure of identification with women's group interests. The correlation between feminist attitudes and women's group interests was significant and positive ( $r=.327$ for the whole sample; $r=.291$ for women only, $p<.001$ ).

Psychological autonomy is measured by five questions which explore attitudes about relations between husbands and wives on such matters as career, family decisions, and women's needs for protection. For example, respondents were asked to indicate agreement/disagreement on a four-point response scale with the following statement: "A woman's life cannot be fully satisfying without a husband and family" The items, developed specifically for this survey, were found to be reliable in pre-tests. Scores were recoded, standardized, 
and summed for a scale score. A high score indicates greater autonomy from men. The five-item scale produced a single factor solution (Eigenvalue $=$ 2.564) and an Alpha reliability of .759.

\section{Analysis}

\section{Gender and Representation: Comparisons of Men and Women}

The survey reveals significant differences between men and women on the strength of their preferences for descriptive representation. Table 1 reports the frequencies of responses on the individual questions which form the descriptive representation scale. On three of the four questions, a higher percentage of women than men preferred someone of the same gender.

玉 Table 1

Frequencies of Responses to Gender Representation Items for Women and Men $(\mathrm{N}=224$ WOMEN; $\mathrm{N}=192 \mathrm{MEN})$.

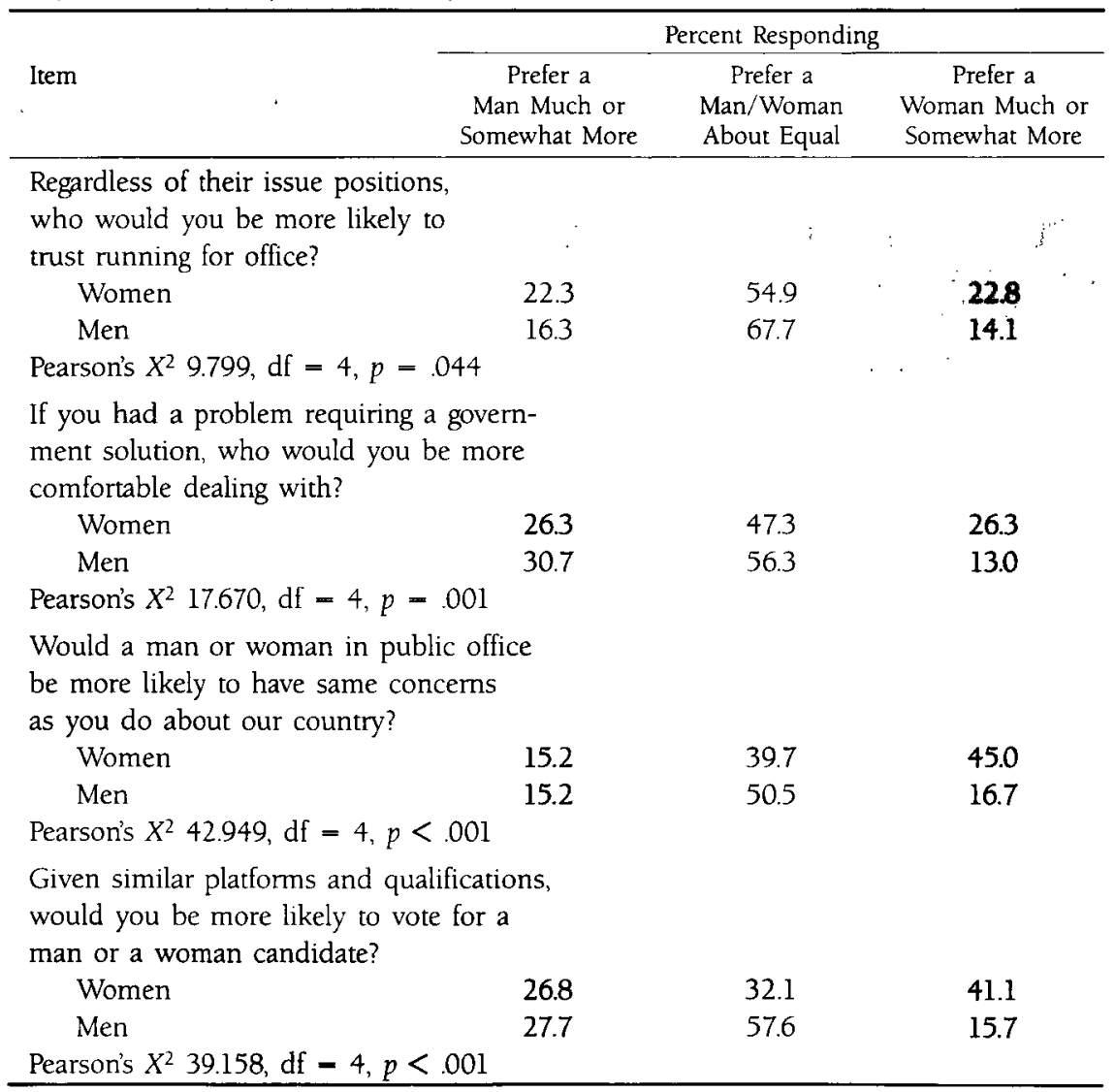


Particularly striking are the results on the questions for which candidate the respondent would vote and which candidate would be most likely to share the same concerns. Men most often chose the gender neutral category of favoring "a man and a woman about equally," but most women indicated that a female candidate would be "somewhat" or "much more" likely to win their vote and share the same concerns on issues. The difference between the mean scores of male and female respondents is greatest on the items of shared concerns ( $\mathrm{X}=2.82$ for men; $\mathrm{X}=3.45$ for women, $p<.001$ ) and on one's voting preference ( $\mathrm{X}=2.90$ for men, $\mathrm{X}=3.22$ for women, $p=.002$ ).

In multiple regression analysis of the full sample with the scale expressed as a preference for female representation, gender continues to be a significant predictor. Controlling for other factors, men are less likely to prefer women as representatives. Conversely, women are more likely to prefer representation by other women. Table 2 shows the regression results.

三 Table 2

Regression of Scale Measuring Preference for Female Representation with

Gender, Feminist Attitudes, Perceptions of Womens Poltical Influence, and Control Variables $(\mathrm{N}=416$, One-Talled Significance Tests)

\begin{tabular}{lrrr}
\hline $\begin{array}{l}\text { Preference for Female } \\
\text { Representation }\end{array}$ & $\mathrm{b}$ & Beta & $\mathrm{p}$ \\
\hline Male Gender & -.622 & -.111 & .004 \\
Identification With & & & \\
Women As a Group & .325 & .107 & .007 \\
Conservative Political & & & \\
Orientation & -.278 & -.166 & $<.001$ \\
Age & -.022 & -.137 & $<.001$ \\
Feminist Attitudes & .639 & .417 & $<.001$ \\
SES & .119 & .100 & .007 \\
intercept & 1.185 & & \\
R-squared & .371 & & \\
p & $<.001$ & & \\
\hline
\end{tabular}

Backward regression model used. Education dropped out of the equation, showing no significant relationship $(p>10)$.

As expected, feminist values and support for women's political interests as a group are positively associated with a preference for female representatives; feminist attitudes have the greatest overall effect. Higher socioeconomic status also shows a significant positive association. Age and conservative political orientation reveal significant negative associations. Together the six variables explain 37 percent of the variance in the scores on the scale. 


\section{Accounting for Differences Among Women}

Table 1 reminds us that not all women think alike. At least 15 percent and sometimes as high as 27 percent of women in the sample said they would trust, vote for or feel more comfortable with a male candidate. Why do some women favor descriptive representation while others do not?

Descriptive representation preferences appear to be strongest among women in their thirties and forties. Dividing the sample into five roughly equivalent age cohorts (19 to 30 years old, 30 to 39,39 to 49,49 to 67 , and 67 to 98 ; each with 42 to 49 respondents), women in their forties scored more than one standard deviation higher on the representation scale than the youngest women and almost three standard deviations above the mean scores of women 49 and older. To confirm the possibility of a significant curvilinear relationship between the descriptive representation scale and age, polynomial regression was performed. Age was recoded to a value equal to 18 minus the respondent's age and then squared. The age-squared variable remains in the equation as the significant association, while age approaches significance.

Carroll presents marital status as a component of psychological autonomy. In this study, only widowed women differed significantly in their preferences for female representatives with a mean score on the scale of one and a half to two standard deviations below that of the other three marital categories of women $\left(\mathrm{Eta}^{2}=.092, p<.001\right)$. However, all but three of the widowed women in the sample are in the two oldest age categories noted above. When the dependent variable is analyzed by categories of marital status and by age category, no clear pattern emerges. Age appears to be the more significant variable.

Table 3 reports the results of multiple regression analysis of the sample of women with all of the key variables. Overall these factors and age explain 38 percent of the variance in women's preference for descriptive representation.

The same curvilinear relationship of age with preference for female representation emerges. Controlling for psychological autonomy, feminist attitudes, and group identification, descriptive representation preferences rise slightly as age increases from younger to middle-aged women but then drops sharply and significantly among older women.

Among the other variables, feminist attitudes have the greatest effect on a woman's preference for female representation. A woman's sense of psychological autonomy and her identification with the political influence of women as a group have smaller but nonetheless significant positive associations with descriptive representation.

A woman's own socioeconomic status does not prove to be a significant predictor of descriptive representation preferences when controlling for the 
三 Table 3

Regression of Scale Measuring Preference for Female Representation with Feminist Attitude Scale, Psychological Autonomy Scale, Women's Group Influence, and Control Variables ( $\mathrm{N}=224$ Women Only, One-Talled SignifiCANCE Tests)

\begin{tabular}{lrrr}
\hline Preference for Female & b & Beta & p \\
Representation & -.042 & -.229 & .162 \\
\hline Age & -.001 & -.409 & .041 \\
Age $^{2}$ & & & \\
Identification With & .443 & .126 & .017 \\
$\quad$ Woman As A Group & & & \\
Conservative Political & -.159 & -.085 & .079 \\
$\quad$ Orientation & .585 & .341 & $<.001$ \\
Feminist Attitudes & .156 & .183 & .004 \\
Psychological Autonomy & .038 & .020 & .368 \\
Economic Status & -.677 & & \\
Intercept & .383 & & \\
R-squared & $<.001$ & & \\
p & & & \\
\hline
\end{tabular}

other variables in the multiple regression analysis. While economic status shows a significant bivariate correlation with the female representation scale, it does not remain significant in multiple regression. Path analysis reveals that economic status has a weak and nonsignificant direct effect, but the indirect effect of economic status through the variable of psychological autonomy is greater and significant.

\section{Discussion}

These results suggest that women are much more "gender conscious" than men in their representation preferences. On the hypothetical voting choice, the gap between men's and women's preferences for someone of the same gender is 13.4 percent, a difference equal to or greater than that in any 1992 U.S. Senate contest involving a man and a woman as candidates (Cook 1994: 224). The gap on the item acknowledging "shared concerns" is almost 30 percent, with women far more likely to see gender as an indicator of a common bond.

In addition to gender the regression analysis of the overall sample reveals that those who are older and hold more conservative political views are less likely to favor a female representative. By contrast, those who have higher socioeconomic status, hold feminist views, and see a need for more political influence for women as a group are more likely to indicate a preference for female representation.

In part, women's stronger impulse for same-gender descriptive representation seems related to substantive political interests. Recall that the hypothetical 
choice of voting for a man or a woman is conditioned by the assumption that both have similar policy stands. More importantly, shared concerns are arguably the necessary precursor to choosing a representative who will act in one's interests. If gender consciousness is a continuum of awareness, as Tolleson Rinehart (1992) suggests, then shared concerns may reflect an initial level of descriptive representation attachment from which some proportion of women move to a voting decision that reflects both "acting for" and "standing for" motivations. In either case, these results suggest that gender is a critical cue whether prompting a voting choice or shaping an affective attachment of shared concerns.

Several forces contribute to (or work against) women's support for other women candidates. The extent to which women are likely to prefer political representation by another woman can be traced to at least four sources. No single variable dominates, but rather there are competing pulls.

First, ideology has an impact. The two ideological measures-on the one hand conservative political views and on the other feminist attitudes- have significant effects in opposite directions. As one might expect, feminist and conservative views are negatively correlated $(r=-.244, p<.001)$. Women who see themselves as more politically conservative are less likely to prefer another woman candidate, while women who hold feminist attitudes are more likely to support another woman. While ideology has been discounted as a influence in voters' decisions, this analysis suggests that at least in hypothetical situations a woman's political orientation may lead her to value gender as a crucial factor in evaluating a candidate.

Second, these results support Carroll's psychological autonomy thesis. Women who see their lives and destinies to be more dependent upon men are also most likely to want to be represented by men. Conversely, women who hold more autonomous views of their lives tend to want other women to represent them.

The results of this study partially confirm Carroll's economic autonomy thesis. Neither marital status, education nor personal income are directly linked to stronger preferences for descriptive representation. Education and income, however, indirectly contribute to the gender gap of representation preferences because better educated and more highly paid women are more likely to feel psychologically autonomous. Marital status seems to be of little consequence.

Third, to the extent that a woman identifies with women's interests as a group, she also is likely to favor being represented by someone who shares those interests-hypothetically another woman. The results here suggest that group interests are a motive force behind some women's preferences for descriptive representation. As political interests become articulated on the 
campaign trail, however, a preference to be represented by another woman may quickly evaporate. Nonetheless, these results are consistent with other research that suggests that gender consciousness leads to identification with women's interests as a group (Tolleson Rinehart 1992).

Finally, and perhaps most relevant to other gender gap analyses, is the finding that women of the "baby boom" generation express distinctly stronger desires to be represented by other women. What cannot be fully determined by this study is the source of such attitudes. More than likely both political socialization and the sum of life experiences contribute to one's support for female candidates.

\section{ConClusion}

This study provides evidence of an underlying "gender gap" in attitudes toward political representation-women are far more likely than men to prefer to be represented by someone of the same gender. While a hypothetical choice may be rendered almost meaningless in the cold reality of the voting booth, this study suggests that gender differences may undergird the particulars of a given race or election. Clearly, a hypothetical choice has limitations; voters don't vote for demographic and political variables. Such limitations suggest a need for additional research perhaps using primary races between male and female candidates.

Nonetheless, the results confirm Tolleson Rinehart's (1992: 152) point that gender conscious women are the ones "who create gender gaps." Importantly, this study reveals a much larger pool of women (45 percent in this study) who feel a female representative is more likely to share the same concerns as they do. Should these women voters make a conscious connection between "shared concerns" and their choice of candidates, the gender gap would grow much larger.

Further research is required to unravel whether the gender gap may be a generational phenomenon. If the stronger preference for descriptive representation among "baby boomers" is largely the product of growing up in the early days of feminism, the gender gap may be merely another blip accompanying this generation. If, however, political support for other women strengthens over a lifetime of formative experiences, then one might expect support for women candidates to increase in the future.

\section{REFERENCES}

Bendyna, May E., and Celinda C. Lake. 1994. "Gender Voting in the 1992 Presidential Election" In Cook, Thomas, and Wilcox, eds., The Year of the Woman: Myths and Realities. Boulder, CO: Westview. 
Campbell, Angus, Philip E. Converse, Warren E. Miller, and Donald E. Stokes 1960. The American Voter New York: Wiley.

Carroll, Susan. 1987. "Women's Autonomy and the Gender Gap: 1980 and 1982." In Carol M. Mueller, ed., The Politics of the Gender Gap. Beverly Hills: Sage. Converse, Philip E. 1964. "The Nature of Belief Systems in Mass Publics." In David E. Apter, ed., Ideology and Discontent New York: Free Press.

Cook, Elizabeth Adell. 1994. "Voter Responses to Women Senate Candidates." In Cook, Thomas, and Wilcox, eds., The Year of the Woman: Myths and Realities. Boulder, CO: Westview.

Cook, Elizabeth Adell, Sue Thomas, and Clyde Wilcox, eds. 1994. The Year of the Woman: Myths and Realities. Boulder, CO: Westview.

Darcy, R., Susan Welch, and Janet Clark. 1987. Women, Elections, and Representation. New York: Longman.

Deitch, Cynthia. 1988. "Sex Differences in Support for Government Spending." In Carol M. Mueller, ed., The Politics of the Gender Gap. Beverly Hills: Sage

Eulau, Heinz, and Paul D. Karps. 1977. "The Puzzle of Representation: Specifying Components of Responsiveness." Legislative Studies Quarterly 2: 233-54.

Frankovic, Kathleen A. 1982. "Sex and Politics: New Alignments, Old Issues." PS 15: 439-48.

Gurin, Patricia. 1986. "The Political Consequences of Women's Statuses." In F. J Crosby, ed., Spouse Parent Worker. New Haven: Yale University Press.

Huddy, Leonie, and Nayda Terkildsen. 1993a. "Gender Stereotypes and the Perception of Male and Female Candidates." American Journal of Political Science 37: $117-47$.

1993b. "The Consequences of Gender Stereotypes for Female Candidates at Different Levels and Types of Offices." Political Research Quarterly 46: 503-26.

Klein, Ethel. 1984. Gender Politics: From Consciousness to Mass Politics. Cambridge, MA: Harvard University Press.

Mandel, Ruth, and Debra Dodson. 1992. "Do Women Officeholders Make a Difference?" In Sara E. Rix, ed., The American Woman New York: Norton.

Mezey, Susan Gluck. 1994. "Increasing the Number of Women in Office: Does It Matter." In Cook, Thomas and Wilcox, eds., The Year of the Woman: Mythes and Realities. Boulder, CO: Westview.

Mueller, Carol M., ed. 1987. The Politics of the Gender Gap. Beverly Hills. Sage.

Niemi, Richard G., and Herbert F. Weisberg, eds. 1984. Controversies in Voting Behavior, 2nd ed. Washington, DC: CQ Press.

Neuman, W. Russell. 1986. The Paradox of Mass Politics. Cambridge, MA: Harvard University Press.

Pitkin, Hanna. 1967. The Concept of Representation. Berkeley: University of California Press.

Poole, Keith T., and L. Harmon Ziegler. 1985. Women, Public Opinion and Politics. New York: Longman.

Sapiro, Virginia. 1991. "Feminism: A Generation Later." The Annals of the American Academy of Political and Social Science 514: 10-22. 
Sears, David O., and Leonie Huddy. 1990. "On the Origins of Political Disunity Among Women." In Louise A. Tilly and Patricia Gurin, eds., Women, Politics and Change. New York: Russell Sage Foundation.

Thomas, Sue. 1994. How Women Legislate. Oxford: Oxford University Press.

Tolleson Rinehart, Sue. 1992. Gender Consciousness and Politics. New York: Routledge. 